\title{
Vantagens da utilização de antibióticos encapsulados em lipossomas para o combate de infecções causadas por enterobactérias
}

\author{
Advantages of using liposome-encapsulated antibiotics to fight infections caused by enterobacteria \\ Ventajas de usar antibioticos encapsulados en liposomas para combatir infecciones causadas por \\ enterobactérias
}

Recebido: 25/04/2021 | Revisado: 03/05/2021 | Aceito: 08/05/2021 | Publicado: 26/05/2021

\author{
Júlio Eduardo Barbosa da Silva \\ ORCID: https://orcid.org/0000-0001-6101-0606 \\ Faculdade São Miguel, Brasil \\ E-mail: julio_barbosa100@outlook.com \\ Jaqueline Barbosa de Souza \\ ORCID: https://orcid.org/0000-0001-9683-5536 \\ Universidade Federal de Pernambuco, Brasil \\ E-mail: jaqueline.bsouza@ufpe.br \\ Daniel Charles dos Santos Macêdo \\ ORCID: https://orcid.org/0000-0002-2356-5149 \\ Universidade Federal de Pernambuco, Brasil \\ E-mail: daniel.csmacedo@ufpe.br \\ Luís André de Almeida Campos \\ ORCID: https://orcid.org/0000-0002-9849-922X \\ Universidade Federal de Pernambuco, Brasil \\ E-mail: luis.andre@ufpe.br \\ Isabella Macário Ferro Cavalcanti \\ ORCID: https://orcid.org/0000-0002-7889-3502 \\ Universidade Federal de Pernambuco, Brasil \\ E-mail:isabella.cavalcanti@ufpe.br
}

\begin{abstract}
Resumo
Introdução: O tratamento de doenças causadas por enterobactérias é um desafio cada vez maior. Esse problema resulta na ineficiência dos antibióticos combaterem os patógenos ou estimularem a fagocitose de células do sistema reticuloendotelial, principalmente contra bactérias que se instalam e se multiplicam no interior de células fagocíticas. Alguns antibióticos são ineficazes em adentrar as células ou tem sua capacidade reduzida pela membrana plasmática. Assim, a comunidade científica reúne esforços buscando novas alternativas terapêuticas que ultrapassem essas limitações. Os lipossomas são nanocarreadores lipídicos capazes de encapsular antibióticos, visando o aumento na especificidade da entrega, a concentração de compostos entregues ao local, manter a concentração plasmática dos fármacos e proteger os princípios ativos. Assim, o objetivo dessa revisão foi descrever as principais propriedades lipossomais, enfatizando as vantagens de utilizar essas vesículas lipídicas para administração de antibióticos frente a infecções causadas por enterobactérias. Metodologia: Trata-se de uma revisão bibliográfica através de buscas nas bases eletrônicas nacionais e internacionais selecionando artigos de 2007 a 2020 utilizando os descritores: Bactérias gram-negativas, Resistência bacteriana, Antimicrobianos e Nanotecnologia. Resultados: Lipossomas catiônicos e furtivos constituídos principalmente por colesterol, PEG, fosfatidilcolina e carboximetilquitosana encapsulando fármacos como amoxicilina, ciprofloxacina, cloxacilina, vancomicina, azitromicina, amoxicilina, cefepime, gentamicina e cefotaxime demonstraram atividade antibacteriana. Lipossomas encapsulando fármacos como cloranfenicol, azitromicina, gentamicina e polimixina B apresentaram maior eficiência antibiofilme frente a enterobactérias quando comparados aos fármacos não encapsulado. Conclusão: Os resultados mostraram que os lipossomas apresentam potencial terapêutico significativo para o tratamento de infecções causadas por enterobactérias.
\end{abstract}

Palavras-chave: Bactérias gram-negativas; Resistência bacteriana; Antimicrobianos; Nanotecnologia.

\begin{abstract}
Introduction: The treatment of diseases caused by enterobacteria is an increasing challenge. This problem results from the inefficiency of antibiotics to fight pathogens or to stimulate phagocytosis of cells of the reticuloendothelial system, mainly against bacteria that install and multiply inside phagocytic cells. Some antibiotics are ineffective at entering cells or have their capacity reduced by the plasma membrane. Thus, the scientific community joins efforts seeking new therapeutic alternatives that overcome these limitations. Liposomes are lipid nanocarriers capable of encapsulating antibiotics, aiming at increasing the specificity of delivery, the concentration of compounds delivered to
\end{abstract}


the site, maintaining the plasma concentration of drugs and protecting the active molecules. Thus, the objective of this review was to describe the main liposomal properties, emphasizing the advantages of using these lipid vesicles to administer antibiotics against infections caused by enterobacteria. Methodology: This is a bibliographic review through searches in national and international electronic databases, selecting articles from 2007 to 2020 using the descriptors: Gram-negative bacteria, bacterial resistance, antimicrobials and nanotechnology. Results: Cationic and furtive liposomes consisting mainly of cholesterol, PEG, phosphatidylcholine and carboxymethyl chitosan encapsulating drugs such as amoxicillin, ciprofloxacin, cloxacillin, vancomycin, azithromycin, amoxicillin, cefepime, gentamicin and cefotaxime have shown antibacterial activity. Liposomes encapsulating drugs such as chloramphenicol, azithromycin, gentamicin and polymyxin B showed greater antibiofilm efficiency compared to enterobacteria when compared to non-encapsulated drugs. Conclusion: The results showed that liposomes have significant therapeutic potential for the treatment of infections caused by enterobacteria.

Keywords: Gram-negative bactéria; Bacterial resistance; Antimicrobials; Nanotechnology.

\section{Resumen}

Introducción: El tratamiento de enfermedades causadas por enterobacterias es un desafío cada vez mayor. Este problema se debe a la ineficacia de los antibióticos para combatir patógenos o para estimular la fagocitosis de células del sistema reticuloendotelial, principalmente contra bacterias que se instalan y multiplican dentro de las células fagocíticas. Algunos antibióticos son ineficaces para ingresar a las células o tienen su capacidad reducida por la membrana plasmática. De esta forma, la comunidad científica une esfuerzos en la búsqueda de nuevas alternativas terapéuticas que superen estas limitaciones. Los liposomas son nanoportadores de lípidos capaces de encapsular antibióticos, con el objetivo de aumentar la especificidad de la administración, la concentración de compuestos administrados al sitio, mantener la concentración plasmática de los medicamentos y proteger los principios activos. Así, el objetivo de esta revisión fue describir las principales propiedades liposomales, enfatizando las ventajas de utilizar estas vesículas lipídicas para administrar antibióticos frente a infecciones causadas por enterobacterias. Metodología: Se trata de una revisión bibliográfica mediante búsquedas en bases de datos electrónicas nacionales e internacionales, seleccionando artículos de 2007 a 2020 utilizando los descriptores: Bacterias gramnegativas, Resistencia bacteriana, Antimicrobianos y Nanotecnología. Resultados: Liposomas catiónicos y furtivos constituidos principalmente por fármacos encapsulantes de colesterol, PEG, fosfatidilcolina y carboximetilquitosano como amoxicilina, ciprofloxacina, cloxacilina, vancomicina, azitromicina, amoxicilina, cefepima, gentamicina y cefotaxima. Los liposomas que encapsulan fármacos como cloranfenicol, azitromicina, gentamicina y polimixina B mostraron una mayor eficacia antibiofilm en comparación con las enterobacterias en comparación con los fármacos no encapsulados. Conclusión: Los resultados mostraron que los liposomas tienen un potencial terapéutico significativo para el tratamiento de infecciones causadas por enterobacterias.

Palabras clave: Bacterias gram negativas; Resistencia bacteriana; Antimicrobianos; Nanotecnología.

\section{Introdução}

A terapia medicamentosa atual para as infecções causadas por enterobactérias é um desafio na clínica, devido, principalmente, ao fato de algumas bactérias serem tolerantes aos fármacos e persistirem devido à resistência bacteriana (Abed \& Couvreur, 2014; Lewis, 2010; Kumar et al., 2017; Zhang, 2014). A resistência aos agentes antimicrobianos é uma condição natural que é acelerada por vários fatores, dentre eles o uso irracional de antimicrobianos causando maiores complicações no combate a esses patógenos. Essa resistência pode acontecer através de mutações genéticas ou métodos de recombinação bacteriana, dificultando a terapia medicamentosa (Aghapour et al., 2019; Alotaibi, 2019; Montso et al., 2019). Além da aquisição de resistência devido a alterações genéticas, as bactérias também são capazes de formar biofilmes que são considerados um mecanismo de sobrevivência bacteriano além de dificultar a interação entre o fármaco e as bactérias (Kumar et al., 2017).

Diversos hospitais europeus relataram surtos desde a década de 90, afirmando a preocupação epidemiológica sobre esses patógenos multidroga-resistentes (MDR). A Organização Mundial de Saúde (OMS) em 2017 lançou um catálogo de 12 famílias de bactérias MDR que representam uma ameaça para saúde humana. A lista foi criada com o intuito de promover a pesquisa e desenvolvimento de novos antibióticos para o tratamento dessas bactérias. Dentre essas bactérias que podem causar infecções graves, frequentementes e mortais, estão incluídas as Enterobacteriaceae como E. coli, Klebsiella sp., Serratia sp. e Proteus sp. (OPAS, 2017). 
Uma das principais famílias bacterianas patogênicas que possuem ou adquirem resistência são as enterobactérias. Enterobacteriaceae são uma grande família de bactérias Gram-negativas que habitam naturalmente o sistema gastrointestinal de vários animais, mas que também possuem algumas bactérias patogênicas, como Escherichia coli, Shigella spp., Salmonella enterica, Klebsiella pneumoniae, dentre outras (Cohen et al., 2016; Porcheron et al., 2013).

O tratamento de infecções causadas por enterobactérias possui várias barreiras a serem ultrapassadas, dentre elas, a baixa biodisponibilidade, neurotoxicidade, nefrotoxicidade e baixa penetração dos fármacos nas células infectadas, diminuindo assim sua eficácia e a adesão do paciente à terapia (Abed \& Couvreur, 2014; Kumar et al., 2017; Li, 2018; Moyá et al., 2019). Portanto, estudos sugerem a utilização de nanocarreadores para aumentar a biodisponibilidade, concentração local de antibióticos, diminuição de toxicidade dos fármacos para melhor combater esses patógenos. Diversos nanocarreadores podem ser utilizados para encapsular antibióticos, dentre eles, os lipossomas (Abed \& Couvreu. 2014; Akbarzadeh et al., 2013).

Os lipossomas são nanocarreadores utilizados na entrega de fármacos em locais estratégicos de infecção ou no tratamento do câncer e de outras doenças. Os lipossomas são compostos por um centro aquoso revestido por bicamadas lipídicas, constituindo-se como sistemas ideais para o transporte de antimicrobianos para o local de ação, podendo incorporar tanto fármacos hidrofílicos no centro aquoso, quanto hidrofóbicos na bicamada lipídica (Daraee et al., 2016; Filipczak et al., 2020). O uso de lipossomas como nanocarreadores de fármacos tem como principais objetivos aumentar a concentração desses fármacos no seu local de ação, aumentar a penetração dos fármacos nas células infectadas e reduzir a toxicidade dos fármacos (Akbarzadeh et al., 2013).

O primeiro fármaco a ser encapsulado em lipossoma e aprovada pela Food and Drug Administration (FDA) foi a doxorrubicina, um agente anticâncer, em 1995 (Huh \& Kwon, 2011). Desde então, muitos estudos veem sendo realizados encapsulando antimicrobianos em lipossomas (Filipczak et al., 2020; Loh et al., 2021; Moyá et al., 2019).

Assim, o objetivo dessa revisão foi descrever as principais propriedades lipossomais, enfatizando as vantagens de utilizar essas vesículas lipídicas para administração de antibióticos frente a infecções causadas por enterobactérias.

\section{Metodologia}

Trata-se de uma revisão bibliográfica de abordagem qualitativa do tipo exploratória através de buscas nas bases eletrônicas nacionais e internacionais Medline, Scientific Eletronic Library On-line (SCIELO), Scholar Google (Google Acadêmico), Pubmed e Biblioteca virtual de saúde (Bvs), selecionando artigos publicados entre 2007 a 2020 apenas em inglês sobre o tema utilizando os seguintes descritores: Bactérias gram-negativas, Resistência bacteriana, Antimicrobianos e Nanotecnologia (Estrela, 2018).

\section{Resultados e Discussão}

\subsection{Problemática das infecções causadas por enterobactérias}

As enterobactérias são uma grande família de bactérias Gram-negativas, bacilos anaeróbicos facultativos não formadores de esporos, onde sua maioria é capaz de crescer em temperaturas entre 25 e $37^{\circ} \mathrm{C}$. Existem em torno de 53 gêneros de Enterobacteriaceae, dos quais mais de 170 espécies já foram nomeadas (Kang et al., 2018; Santos et al., 2020). Este grupo é amplamente encontrado na natureza como no solo, água, vegetais e na microbiota gastrointestinal de humanos e animais, onde a Escherichia coli é a espécie mais abundante da família. Dentre os 53 gêneros de Enterobacteriaceae, cerca de 26 gêneros foram associados a infecções em humanos (Linninge et al., 2018; Pati et al., 2017; Santos et al., 2020).

Os principais patógenos de grande importância epidemiológica causadores de morbidade e mortalidade mundial e o surgimento de MDR são Salmonella, Escherichia, Shigella e Yersinia. As principais infecções associadas a enterobactérias são 
bacteremia, infecções nas vias respiratórias inferiores, infecções na pele, infecções no trato urinário (ITUs), infecções intraabdominais, infecções oftálmicas, dente outras (Kang et al., 2018; Pati et al., 2017).

Quando as bactérias MDR infectam e provocam doenças em um indivíduo, elas representam sérios desafios para o tratamento, sendo considerada a segunda causa de mortalidade no mundo (Alhariri et al., 2017). A resistência desses microrganismos é acelerada devido ao uso indiscriminado de antibióticos, junto com a liberação de grandes quantidades de antibióticos no meio ambiente através das águas residuais de hospitais. Esses resíduos não são tratados e podem impactar o nicho bacteriano aquático e causar alterações genéticas, resultando também na resistência bacteriana a fármacos (Carole et al., 2018).

Esses patógenos são capazes de adquirir diferentes mecanismos de resistência por meio de diversos genes que modificam a membrana externa da bactéria, alteram a estrutura celular interna, modificam os transportadores de membrana como porinas e produzem bombas de efluxo, produzem enzimas como $\beta$-lactamases de espectro estendido (ESBLs) e carbapenemases como, por exemplo: Klebsiella oxytoca que possui enzimas K1 $\beta$-lactamases que causam resistência a cefalosporina e aztreonam; Proteus vulgaris, que tem a capacidade de resistir ao tratamento de antibióticos devido à expressão de $\beta$-lactamases cromossômicas, dentre outras. Os genes que codificam essas enzimas também podem ser encontrados nos cromossomos e plasmídeos da $E$. coli que produzem $\beta$-lactamases cromossômicas que auxiliam na resistência aos antibióticos. A resistência bacteriana pode ser transferida entre espécies através de alguns genes móveis que podem se disseminar principalmente através de viajantes internacionais que correm o risco de adquirir variantes de Enterobacteriaceae e, consequentemente, adquirir as infecções causadas por essas bactérias (Aghapour et al., 2019; Alhariri et al., 2017; Alotaibi, 2019; Babushkina et al., 2019; Montso et al., 2019; Ruppé et al., 2017).

Além da resistência aos antibióticos, os microrganismos apresentam a capacidade de viver em biofilmes, inclusive as Enterobacteriaceae (Davin-Regli et al., 2019). Biofilmes são definidos como uma comunidade estruturada de microrganismos envolvidos por uma matriz autoproduzida a partir de substâncias poliméricas extracelulares que se aderem à superfície inerte ou viva, formando assim um mecanismo de sobrevivência microbiano (Cai et al., 2018; Narayana \& Srihari, 2019; RamosVivas et al., 2019). A matriz consiste na agregação de polissacarídeos, proteínas e DNA, que favorece um nicho ecológico criando um compartimento que permite a sobrevivência ao estresse do microambiente local e canaliza para evolução, cooperação comunitária, disseminação e ressurgimento de novas infecções. A matriz também atua como uma barreira protetora que impede a interação de fármacos garantindo a sobrevivência microbiológica. Dentro do biofilme pode existir uma única espécie de bactérias ou um consórcio de multiespécies microbianas (Haussler \& Fuqua, 2013; Kumar et al., 2017).

Estudos recentes mostram a capacidade de Enterobacteriaceae viverem em biofilmes como o estudo realizado por Ramos-Vivas et al. (2018), que demonstrou biofilmes de Escherichia coli, Klebisiella pneumoniae e Enterobacter spp. em amostras de receptores de transplante de órgão sólidos como rins, fígado e pâncreas. Nesse estudo foram isoladas 39 cepas antes do transplante e 179 cepas após o transplante. Destas cepas, muitas viviam em biofilme, cerca de $73 \%$ de K. pneumoniae, $16 \%$ de E. coli e $4 \%$ de Enterobacter spp.

As infecções nosocomiais causadas por esses patógenos MDR representam um problema global, tornando-se nos últimos anos uma das principais causas de morte (Ichim et al., 2019). Assim, grupos de pesquisas buscam estratégias terapêuticas eficazes para o tratamento de infecções causadas por esses patógenos, podendo se basear na utilização da nanotecnologia farmacêutica através do uso dos lipossomas.

\subsection{Lipossomas e suas vantagens para a encapsulação de fármacos}

Lipossomas podem ser definidos como vesículas lipídicas com um compartimento interno aquoso, capaz de encapsular fármacos hidrofílicos e hidrofóbicos. Os lipossomas são constituídos por fosfolipídeos e colesterol, onde os lipídeos 
mais utilizados possuem em sua constituição fosfatidilcolina, fosdatidilserina, fosfatidilglicerol e outros fosfolipídeos naturais e sintéticos (Akbarzadeh et al., 2013; Batista et al., 2007; Has \& Sunther, 2019), e apresentam diâmetro de vesícula com medidas que variam de 20 a 5000 nm (Abed \& Couvreur. 2014; Moyá et al., 2019). Devido a essa composição, os lipossomas são biocompatíveis e biodegradáveis (Akbarzadeh et al., 2013; Aryasomayajula et al., 2017; Has \& Sunthar, 2019).

Os lipossomas podem possuir uma única camada, chamado de unilamelar ou mais camadas, chamados de multilamelares (Daraee et al., 2014). Eles possuem natureza anfifílica devido aos dois compartimentos: um hidrofílico/aquoso, localizado no interior do lipossoma e outra lipofílica, localizado entre suas membranas. Além disso, a membrana externa do lipossoma pode possuir carga de acordo com a finalidade que o lipossoma está sendo preparado e para evitar a agregação das vesículas, aumentando sua estabilidade (Figura 1) (Batista et al., 2007; Rukavina \& Vanić, 2016).

Figura 1. Características estruturais de lipossomas: convencionais, furtivos, sítio-específicos e pH sensíveis.

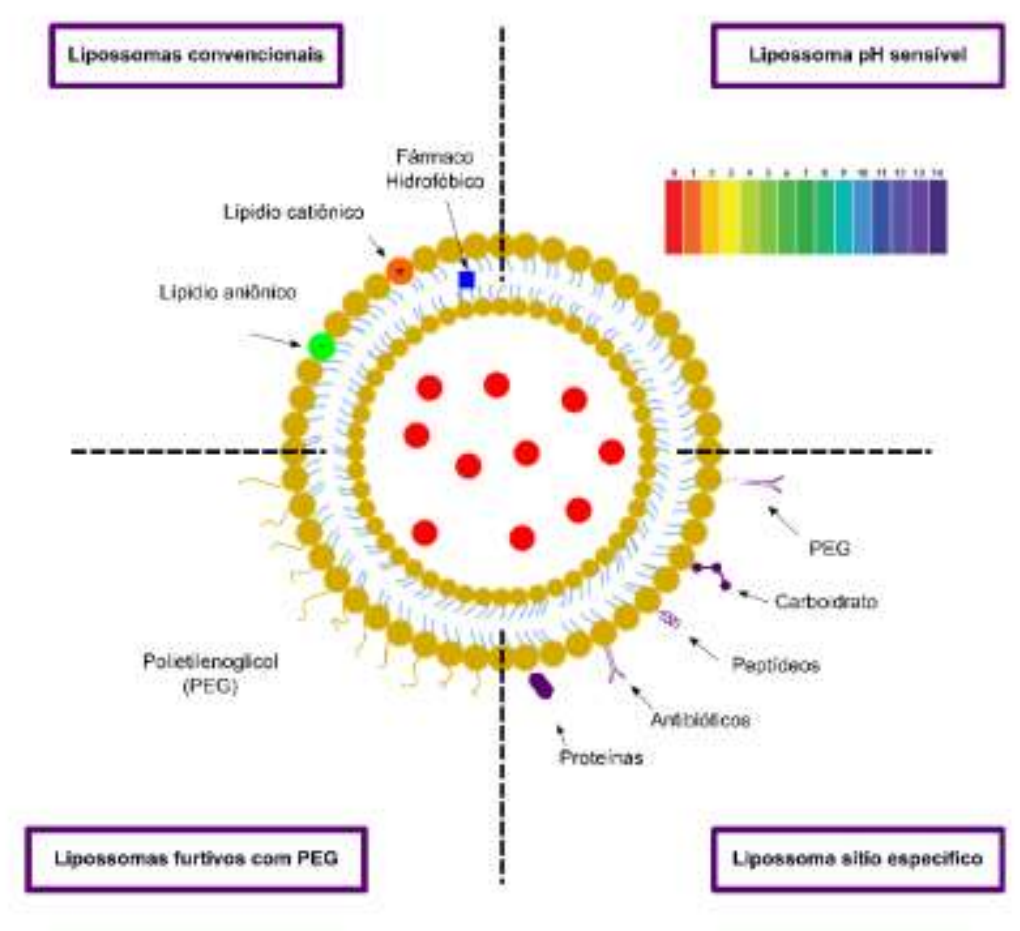

Fonte: Autores (2021).

As principais vantagens da utilização dos lipossomas na terapia, inclusive na terapia antimicrobiana, são a possibilidade de direcionamento intracelular do fármaco, aumento da eficácia do fármaco e redução da sua toxicidade (Moghimipour \& Handali, 2013).

Os lipossomas possuem ainda a capacidade de criar um ambiente protetor para fármacos, garantindo a estabilidade e manutenção plasmática do antibiótico para uma melhor eficácia no tratamento de infecções. Eles podem também melhorar a biodisponibilidade e biodistribuição in vivo dos fármacos, além de preservar as propriedades farmacocinéticas e farmacodinâmicas dos fármacos encapsulados (Monteiro et al., 2015).

A primeira geração de lipossoma conhecida como lipossomas convencionais, são formados por uma bicamada lipídica biocompatível e biodegradável, que encapsulam muitos agentes terapêuticos. Entretanto, quando administrados in vivo, são capturados rapidamente na corrente sanguínea, levados até o sistema retículo endotelial (SRE), ou fagocítico mononuclear, que metaboliza o lipossoma, diminuindo, assim, a sua concentração na circulação sanguínea e acumulando-os nos órgãos como 
fígado, baço e medula óssea (Aryasomayajula et al., 2017; Briones et al., 2007; Ghatage et al., 2017; Hamblin et al., 2014; Has \& Sunthar, 2019).

Devido ao compartimento lipídico dos lipossomas, as maneiras de interação dessas vesículas com os fagossomos são: interação por fusão, onde a camada lipídica e a membrana plasmática celular misturam-se e difundem-se, permitindo assim que agentes internalizados no seu núcleo aquoso ou lipofílico sejam liberados diretamente no meio intracelular das células-alvos; a troca lipídica entre a vesícula lipossomal e a célula do hospedeiro, dada por proteínas de troca lipídica presentes na superfície celular; absorção específica ou não de lipossoma com a membrana celular que ocorre na ausência de fusão entre a camada lipossomal e membrana celular, decorrente das forças atrativas (interações eletrodinâmicas, van de Waals, inserção hidrofóbica ou pontes de hidrogênio) que exercem forças repulsivas, como interações eletroestáticas, estéricas, protrusão e adsorção de vesículas lipídicas na membrana de fagossomos; os lipossomas podem também ser desestabilizados por componentes da membrana celular quando adsorvidos em superfície, liberando seu material interno no citoplasma via micropinocitose; ou a interação por endocitose, onde células do sistema de fagócitos mononucleares englobam os lipossomas com prolongamentos formando endossomos, onde os lipossomas se fundem resultando em formação de um fagossomos e as enzimas lisossomais degradam os fosfolipídeos da vesícula e liberam seu substrato no citoplasma (Alhariri et al., 2013; Huh \& Kwon, 2011; Moghimipour \& Handali, 2013; Monteiro et al., 2015).

Após alguns anos, os pesquisadores conseguiram desenvolver lipossomas de segunda geração também chamados de lipossomas furtivos ou stealth. Esses lipossomas possuem a capacidade de aumentar o tempo de circulação dos lipossomas na corrente sanguínea sem serem fagocitados e metabolizados pelo SRE, devido à inclusão de polímeros como o polietilenoglicol (PEG) na superfície lipossomal. As cadeias de PEG podem ser incorporadas à superfície do lipossoma durante a preparação ou após sua formação por pós-inserção. Essas cadeias possuem a capacidade de diminuir a hifrofobicidade, imunogenicidade e aumentar a estabilidade impedindo a opsonisação de fagócitos e sua remoção da circulação sanguínea (Aryasomayajula et al., 2017; Ghatage et al., 2017).

A terceira geração de lipossomas desenvolvidos são os lipossomas sítio-específicos. Esses nanocarreadores possuem a capacidade de direcionar os fármacos encapsulados a lugares específicos como tecidos tumorais e tecidos infectados por microrganismos, baseado na fixação de ligantes à superfície dos lipossomas, tais como anticorpos, proteínas, peptídeos e aptâmeros, que se ligam a componentes específicos presentes no local desejado. Essa funcionalização da superfície induz modificações na entrega do medicamento para a célula alvo, podendo estimular a endocitose e aumento da resposta após a ligação com o receptor celular específico (Aryasomayajula et al., 2017; Has \& Sunthar, 2019).

Além desses lipossomas citados, outros tipos também vêm sendo investigados como os lipossomas sensíveis ao pH para desintegração em meio ácido e lipossomas termossensíveis para entrega por calor. Os lipossomas sensíveis ao pH são nanotransportadores sensíveis a estímulos sensíveis ao pH. Esses lipossomas podem sem conjugados de lipídio-polímeros como PEG-HZ-PE para fornecer uma membrana com função de longa circulação permitindo assim o lipossoma encontrar um ambiente de $\mathrm{pH}$ ácido ou básico para entrega e penetração apropriada. São capazes de entregar fragmentos de genes e fármacos ao citoplasma através da via endocítica, sendo desestabilizados no estágio endossomal devido ao seu potencial fusogênico, evitando assim a degradação d fármaco e estimulando a liberação no citoplasma celular (Aghdam et al., 2019; Aryasomayajula et al., 2017).

Os lipossomas termossensíveis (LTS) são carreadores sensíveis a estímulos de hipertermia onde os lipídeos de sua composição passam por transições de fase quando expostos a temperaturas elevadas, ou seja, temperatura de transição de fase (Tm). Tm é quando o estado físico dos lipídeos muda de uma fase de gel para uma fase líquida permeável criando limites que resultam na liberação do medicamento através da permeabilidade da membrana. A liberação do fármaco encapsulado em LTS pode depender do aumento da permeabilidade da bicamada lipídica resultante do aquecimento da temperatura acima da $\mathrm{Tm}$ da 
mistura de lipídeos. Os lipídeos constituintes dos LTS são DPPC, DSPC, PEG, fosfatidilcolina e colesterol. Uma das vantagens do LTS é a possibilidade de conjugar ligantes específicos do alvo aumentando a retenção do fármaco a lugares estratégicos, melhorando assim seu uso terapêutico (Aghdam et al., 2019; Dou et al., 2017).

\subsection{Encapsulação de antibióticos em lipossomas para o tratamento de infecções causadas por enterobactérias}

Os lipossomas podem atuar nas células bacterianas por meio da adesão à membrana citoplasmática e à parede celular, penetrando-as, e, consequentemente, afetando a função celular, interagindo com estruturas celulares como as proteínas ou o DNA, induzindo a formação de espécies reativas de oxigênio (EROs) e radicais livres (Figura 2) (Aljihani et al., 2020; Vanić et al., 2019).

Figura 2. Atividade antibacteriana de antibióticos encapsulados em lipossomas.

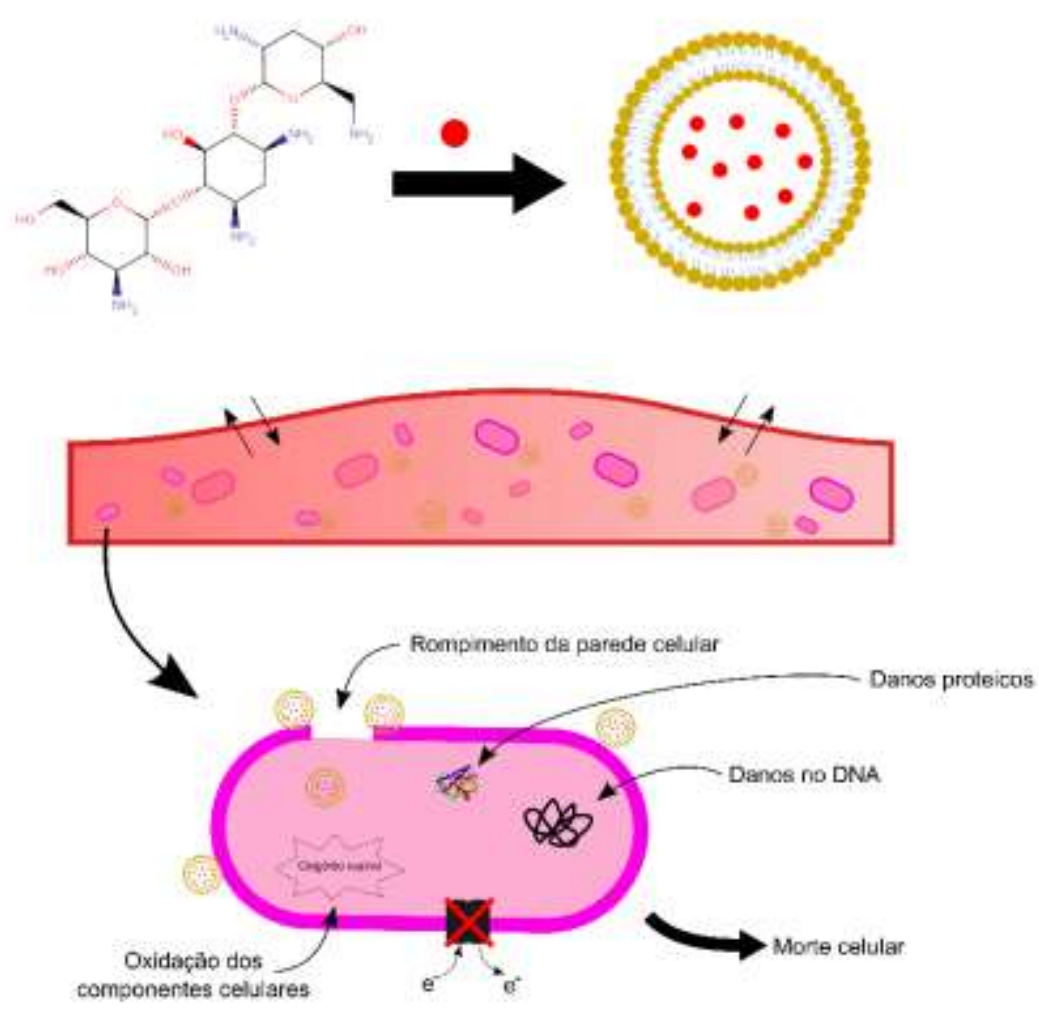

Fonte: Autores (2021).

Os estudos da literatura sobre a entrega de antibióticos encapsulados em lipossomas comprovam que essa estratégia terapêutica é mais eficaz do que a entrega de antibióticos livres frente a infecções causadas por enterobactérias (El-Hammadi \& Arias, 2019; Trucillo et al., 2020; Vassallo et al., 2020). Além disso, devido ao significado clínico da resistência bacteriana, as pesquisas têm sido intensificadas a fim de possibilitar a utilização de fármacos com espectro de ação limitada frente a isolados resistentes, que pode ser promovida por meio da encapsulação em lipossomas (Cé et al., 2021). Estudos que comprovaram essa eficácia encontram-se descritos na Tabela 1. 
Tabela 1. Atividade antibacteriana de antibióticos encapsulados em lipossomas frente a enterobactérias.

\begin{tabular}{|c|c|c|c|c|}
\hline Fármaco & Tipo de lipossoma & Microrganismo & $\begin{array}{c}\text { Atividade } \\
\text { antibacteriana }\end{array}$ & Referências \\
\hline Ácido fusídico & Convencional & $\begin{array}{c}\text { Isolados clínicos de } \\
\text { Klebsiella } \\
\text { pneumoniae }\end{array}$ & CIM: $150 \mu \mathrm{g} / \mathrm{mL}$ & $\begin{array}{l}\text { Nicolosi et al., } \\
2015\end{array}$ \\
\hline & & Escherichia coli & CIM: $75 \mu \mathrm{g} / \mathrm{mL}$ & \\
\hline Gentamicina & $\begin{array}{l}\text { Catiônico, } \\
\text { convencional }\end{array}$ & $\begin{array}{c}\text { Klebsiella oxytoca } \\
\text { ATCC } 700324\end{array}$ & CIMB: $0,25 \mathrm{mg} / \mathrm{L}$ & Alhariri et al., 2017 \\
\hline $\begin{array}{l}\text { Ciprofloxacino, } \\
\text { Amicacina, } \\
\text { Cloxacilina e } \\
\text { Vancomicina }\end{array}$ & Furtivo & $\begin{array}{l}\text { Isolado clínico de } \\
\text { K. pneumoniae } \\
\text { MDR e } \\
\text { E. coli }\end{array}$ & $\begin{array}{c}\text { Zona de inibição: } 27 \\
\text { a } 40 \mathrm{~mm}\end{array}$ & $\begin{array}{l}\text { Jainamboo et al., } \\
2017\end{array}$ \\
\hline $\begin{array}{l}\text { Cefotaxime + } \\
\text { Ácido elágico }\end{array}$ & Convencional & E. coli & $\begin{array}{c}\text { Zona de inibição: } 54 \\
\quad \pm 2,1 \mathrm{~mm}\end{array}$ & Asfour et al., 2017 \\
\hline Cloranfenicol & Convencional & $\begin{array}{c}\text { Isolados de } \\
\text { Acinetobacter junii e } \\
\text { E. coli }\end{array}$ & $\begin{array}{c}\text { Diminuição de } 127 \text { e } \\
149 \text { UAF }\end{array}$ & $\begin{array}{l}\text { Dias-Souza et al., } \\
2017\end{array}$ \\
\hline Polimixina B & $\begin{array}{c}\text { Revestido por } \\
\text { quitosana }\end{array}$ & $\begin{array}{c}\text { Isolado clínico de } A \text {. } \\
\text { baumannii }\end{array}$ & CIMB: $8 \pm 2 \mu \mathrm{g} / \mathrm{mL}$ & Fu et al., 2019 \\
\hline Azitromicina & $\begin{array}{l}\text { Convencional } \\
\text { Furtivo }\end{array}$ & E. coli ATCC 8739 & $\begin{array}{l}\mathrm{CIM}_{50}: 7,66 \mu \mathrm{g} / \mathrm{mL} \\
\mathrm{CIM}_{50}: 7,38 \mu \mathrm{g} / \mathrm{mL}\end{array}$ & Vanić et al., 2019 \\
\hline Azitromicina & Convencional & $\begin{array}{l}\text { Isolado clínico de } E \text {. } \\
\text { coli }\end{array}$ & CIM: $0,62 \mu \mathrm{g} / \mathrm{mL}$ & Aljihani et al., 2020 \\
\hline
\end{tabular}

LMG: Laboratorium voor Microbiologie of Universiteit Gent; CIM: Concentração Inibitória Mínima; MDR: Multidroga-resistente; ATCC: American Type Culture Collection; UAF: Unidades Arbitrárias de Fluorescência; CIMB: Concentração Inibitória Mínima do Biofilme. Fonte: Autores (2021).

Nicolosi et al. (2015) encapsularam o ácido fusídico, um agente bacteriostático, em lipossomas convencionais, e testaram sua eficácia frente a isolados clínicos de Escherichia coli e Klebsiella pneumoniae. Os resultados demonstraram CIM de $150 \mu \mathrm{g} / \mathrm{mL}$ para o isolado de K. pneumoniae e $75 \mu \mathrm{g} / \mathrm{mL}$ para E. coli, enquanto o valor de CIM do fármaco livre foi superior a $833 \mu \mathrm{g} / \mathrm{mL}$ para ambas as cepas. Portanto, a encapsulação do ácido fusídico mostrou maior eficiência, devido a capacidade de transportar o fármaco através da membrana celular bacteriana, através de um mecanismo de fusão, facilitando a difusão do fármaco encapsulada na bactéria.

Estudos indicam que há a possibilidade da redução da resistência bacteriana por meio de estratégias que se baseiam na combinação de agentes antimicrobianos co-encapsulados em lipossomas, para tal Asfour, (2017) coencapsularam cefotaxime $(\mathrm{CXM})$ e ácido elágico (AE) em lipossomas convencionais (L-CXM-AE) e avaliaram a atividade antibacteriana frente à isolados de Escherichia coli qual o perfil de resistência. Os L-CXM-AE apresentaram zona de inibição de $54 \pm 2,1$ mm, 
enquanto a formulação sem $\mathrm{AE}$ apresentou halo de $51 \pm 3,1 \mathrm{~mm}$, evidenciando, assim, que o $\mathrm{AE}$ potencializa a atividade antibacteriana do CXM.

Moyá et al. (2019) encapsularam cefepime em lipossomas catiônicos e avaliaram a atividade antibacteriana frente a Escherichia coli. LC apresentaram CIM de $2 \mu \mathrm{g} / \mathrm{mL}$, e assim indicam superioridade na capacidade inibitória desse sistema quando comparado ao fármaco não encapsulado (CIM $=5 \mu \mathrm{g} / \mathrm{mL})$.

Vanić et al. (2019) encapsularam azitromicina em lipossomas convencionais (LCs) e lipossomas contendo propilenoglicol (LPGs) e avaliaram a atividade antibacteriana e antibiofilme frente a Escherichia coli ATCC 8739. LPGs apresentaram maior atividade antimicrobiana com $\mathrm{CIM}_{50}$ de $7,38 \mu \mathrm{g} / \mathrm{mL}$, enquanto o fármaco não encapsulado obteve $\mathrm{CIM}_{50}$

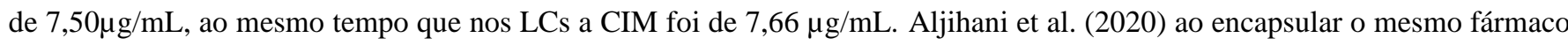
em lipossomas convencionais (LNA) e avaliar a atividade antibacteriana frente ao isolado clínico de Escherichia coli. LNA apresentaram CIM de 0,62 $\mu \mathrm{g} / \mathrm{mL}$, se mostrando mais eficientes quando comparados aos fármacos não encapsulados (CIM = 8-16 $\mu \mathrm{g} / \mathrm{mL}$ ). Sendo assim, estes estudos demonstram a efetividade antibacteriana da encapsulação da azitromicina em lipossomas.

Quanto ao potencial antibiofilme dos fármacos encapsulados em lipossomas, Alhariri et al. (2017), encapsularam gentamicina em lipossomas constituídos por fosfolipídios carregados negativamente e avaliaram a atividade antibiofilme frente a Klebsiella oxytoca ATCC 700324. Esses lipossomas apresentaram CIMB de 0,25 mg/L se mostrando mais eficiente na inibição da formação do biofilme quando comparado ao fármaco não encapsulado (CIMB $=0,5 \mathrm{mg} / \mathrm{L}$ ). Essa inibição observada pode ser resultante da liberação do fármaco de forma mais prolongada e da maior capacidade de penetração no biofilme, permitindo, assim, maior contato do fármaco com as células bacterianas.

Com o mesmo propósito, Fu et al. (2019) encapsularam polimixina B em lipossomas revestidos com quitosana (LPQ) e avaliaram a atividade antibiofilme, mas dessa vez frente a Acinetobacter baumannii. LPQ apresentou CIMB de $8 \pm 2 \mu \mathrm{g} / \mathrm{mL}$, e o fármaco livre $\mathrm{CIMB}=32 \pm 2 \mu \mathrm{g} / \mathrm{mL}$. Dessa forma, é sugerido que os lipossomas com a presença do revestimento por quitosana apresentam interação com a matriz polimérica presente no biofilme, fator que auxilia na internalização do fármaco e aumenta a atividade antibiofilme.

\section{Conclusão}

Os estudos apresentados nessa revisão mostram evidências que a utilização de lipossomas para a entrega de antibióticos para o tratamento das infecções bacterianas é eficaz. Essa estratégia terapêutica torna o tratamento das infecções causadas por enterobactérias mais eficaz, com baixo risco de resistência bacteriana e com menos efeitos colaterais para o paciente.

Os lipossomas são agora cada vez mais usados em ambientes clínicos e são muito populares devido às suas propriedades biocompatíveis. Algumas formulações estão sendo analisadas no mercado e em ensaios clínicos para a melhora do tratamento de infecções causadas por enterobactérias.

Diante da comprovada melhora que os lipossomas promovem na terapêutica de antibióticos contra enterobactérias, fármacos que apresentam baixo índice terapêutico, elevada toxicidade e baixa solubilidade em água são excelentes candidatos a serem veiculados em lipossomas. Desta forma, caso os ativos apresentem as caracterísitcas citadas, o presente trabalho estimula a encapsulação destes fármacos em lipossomas tendo como objetivo aumentar o arsenal terapêutico contra as enterobactérias. 


\section{Agradecimentos}

Julio Eduardo Barbosa da Silva agradece ao Programa Institucional de Iniciação em Desenvolvimento Tecnológico e Inovação (PIBITI/UFPE/CNPq) pela concessão da bolsa. Os autores agradecem ao Conselho Nacional de Desenvolvimento Científico e Tecnológico - CNPq (426065/2018-2) por parte do apoio financeiro deste trabalho.

\section{Referências}

Abed, N. \& Couvreur, P. (2014). Nanocarriers for antibiotics: a promising solution to treat intracellular bacterial infections. International Journal of Antimicrobial Agents, 43 (6), 485-496.

Aghapour, Z., Gholizadeh, P., Ganbarov, K., Bialvaei, A. Z., Mahmood, S. S., Tanomand, A., Yousef M.; Asgharzadeh M.; Yousef B. \& Kafil, H. S. (2019). Molecular mechanisms related to colistin resistance in Enterobacteriaceae. Infection and Drug Resistance, $12,965$.

Aghdam, M. A., Bagheri, R., Mosafer, J., Baradaran, B., Hashemzaei, M., Baghbanzadeh, A., Guardia M. \& Mokhtarzadeh, A. (2019). Recent advances on thermosensitive and $\mathrm{pH}$-sensitive liposomes employed in controlled release. Journal of Controlled Release, $315,1-22$.

Akbarzadeh, A., Rezaei-Sadabady, R., Davaran, S., Joo, S. W., Zarghami, N., Hanifehpour, Y., Samiei M.; Kouhi M. \& Nejati-Koshki, K. (2013). Liposome: classification, preparation, and applications. Nanoscale Research Letters, 8 (1), 1-9.

Alhariri, M., Majrashi, M. A., Bahkali, A. H., Almajed, F. S., Azghani, A. O., Khiyami, M. A., Alyamani E. J.; Aljohani S. M. \& Halwani, M. A. (2017). Efficacy of neutral and negatively charged liposome-loaded gentamicin on planktonic bacteria and biofilm communities. International Journal of Nanomedicine, 12, 6949.

Aljihani, S. A., Alehaideb, Z., Alarfaj, R. E., Alghoribi, M. F., Akiel, M. A., Alenazi, T. H., Al-Fahad J. A., Al Tamimi, S. M., Albakr, T. M., Alshehri, A., Alyahya, S. M., Yassin, A. E. B. \& Halwani, M. A. (2020). Enhancing azithromycin antibacterial activity by encapsulation in liposomes/liposomal-Nacetylcysteine formulations against resistant clinical strains of Escherichia coli. Saudi Journal of Biological Sciences, 27 (11), $3065-3071$.

Alotaibi, F. (2019). Carbapenem-resistant Enterobacteriaceae: an update narrative review from Saudi Arabia. Journal of Infection and Public Health, 12 (4), 465-471.

Aryasomayajula, B., Salzano, G. \& Torchilin, V. P. (2017). Multifunctional liposomes. Methods in Molecular Biology, 1530, 41-61.

Asfour, H. Z. (2017). Cefotaxime combined ellagic acid in a liposomal form for more stable and antimicrobial effective formula. American Journal of Microbiological Research, 5 (5), 113-117.

Babushkina, I. V., Bondarenko, A. S., Ulyanov, V. Y. \& Mamonova, I. A. (2020). Biofilm formation by gram-negative bacteria during implant-associated infection. Bulletin of Experimental Biology and Medicine, 169 (3), 365-368.

Batista, C. M., Carvalho, C. M. B. D. \& Magalhães, N. S. S. (2007). Lipossomas e suas aplicações terapêuticas: Estado da arte. Revista Brasileira de Ciências Farmacêuticas, 43 (2), 167-179.

Bennett, J. E.; Dolin, R. \& Blaser, M. J. (2014). Mandell, douglas, and bennett's principles and practice of infectious diseases: 2-volume set (Vol. 2). Elsevier Health Sciences.

Briones, E., Colino, C. I. \& Lanao, J. M. (2008). Delivery systems to increase the selectivity of antibiotics in phagocytic cells. Journal of Controlled Release, 125 (3), 210-227.

Cai, L., Wang, H., Liang, L., Wang, G., Xu, X. \& Wang, H. (2018). Response of formed-biofilm of Enterobacter cloacae, Klebsiella oxytoca, and Citrobacter freundii to chlorite-based disinfectants. Journal of Food Science, 83 (5), 1326-1332.

Carole, G. M. B. V., Kouadio, G. N., Baguy, O. M., Djénéba, O. G., Ayayi, A., Bertin, T. K., Anatole T. A., Innocent K. K., Kpoda D. S., Eric T., Ali K., Fernique K., Alphonse K., Mireille D. \& Bmr, G. (2018). Antimicrobial resistance profile and molecular characterization of extended-spectrum beta-lactamase genes in enterobacteria isolated from human, animal and environment. Journal of Advances in Microbiology, 10 (1), 1-9.

Cé, R., Pacheco, B. Z., Ciocheta, T. M., Barbosa, F. S., de CS Alves, A., Dallemole, D. R. \& Pohlmann, A. R. (2021). Antibacterial activity against Grampositive bacteria using fusidic acid-loaded lipid-core nanocapsules. Reactive and Functional Polymers, 162 (1), 104876.

Cohen, J.; Powderly, W. \& Opal, S. (2016). Infectious diseases. Elsevier.

Daraee, H., Etemadi, A., Kouhi, M., Alimirzalu, S. \& Akbarzadeh, A. (2016). Application of liposomes in medicine and drug delivery. Artificial Cells, Nanomedicine, and Biotechnology, 44 (1), 381-391.

Davin-Regli, A., Lavigne, J. P. \& Pagès, J. M. (2019). Enterobacter spp.: update on taxonomy, clinical aspects, and emerging antimicrobial resistance. Clinical Microbiology Reviews, 32 (4).

Dias-Souza, M. V., Soares, D. L. \& Dos Santos, V. L. (2017). Comparative study of free and liposome-entrapped chloramphenicol against biofilms of potentially pathogenic bacteria isolated from cooling towers. Saudi Pharmaceutical Journal, 25 (7), 999-1004.

Dou, Y., Hynynen, K. \& Allen, C. (2017). To heat or not to heat: Challenges with clinical translation of thermosensitive liposomes. Journal of Controlled Release, 249, 63-73. 
El-Hammadi, M. M. \& Arias, J. L. (2019). An update on liposomes in drug delivery: a patent review (2014-2018). Expert Opinion on Therapeutic Patents, 29 (11), 891-907.

Estrela, C. (2018). Metodologia científica: ciência, ensino, pesquisa. Artes Médicas.

Filipczak, N., Pan, J., Yalamarty, S. S. K. \& Torchilin, V. P. (2020). Recent advancements in liposome technology. Advanced Drug Delivery Reviews, 156, 0422 .

Fu, Y. Y., Zhang, L., Yang, Y., Liu, C. W., He, Y. N., Li, P. \& Yu, X. (2019). Synergistic antibacterial effect of ultrasound microbubbles combined with chitosan-modified polymyxin B-loaded liposomes on biofilm-producing Acinetobacter baumannii. International Journal of Nanomedicine, 14, $1805-1815$.

Ghatage, T., Jadhav, S. \& Kore, V. (2017). A Review on Stealth Liposomes: Novel Drug Delivery System. International Journal of Scientific Engineering and Technology Research, 6 (14), 2744-2750.

Hamblin, K. A., Armstrong, S. J., Barnes, K. B., Davies, C., Wong, J. P., Blanchard, J. D., Harding S. V., Simpson A. J. H. \& Atkins, H. S. (2014). Liposome encapsulation of ciprofloxacin improves protection against highly virulent Francisella tularensis strain Schu S4. Antimicrobial Agents and Chemotherapy, 58 (6), 3053-3059.

Has, C. \& Sunthar, P. (2020). A comprehensive review on recent preparation techniques of liposomes. Journal of Liposome Research, 30 (4), 336-365.

Haussler, S. \& Fuqua, C. (2013). Biofilms 2012: new discoveries and significant wrinkles in a dynamic field. Journal of Bacteriology, 195 (13), $2947-2958$.

Huh, A. J. \& Kwon, Y. J. (2011). "Nanoantibiotics": a new paradigm for treating infectious diseases using nanomaterials in the antibiotics resistant era. Journal of Controlled Release, 156 (2), 128-145.

Ichim, D. L., Duceac, L. D., Marcu, C., Iordache, A. C., Ciomaga, I. M., Luca, A. C., Goroftef E. R. B.; Mitrea G.; Damir D. \& Stafie, L. (2019). Synthesis and characterization of colistin loaded nanoparticles used to combat multi-drug resistant microorganisms. Revista de Chimie 70 (10).

Jainamboo, M., Gopukumar, S. \& Praseetha, P. (2017). Improving the clinical efficacy of drugs by liposomes against resistant bacteria (Mdr Bacteria) - An in vitro study. International Journal of Pharma and Bio Sciences, 8 (3), $42-57$.

Kang, E., Crouse, A., Chevallier, L., Pontier, S. M., Alzahrani, A., Silué, N., Valois F. X. C.; Montagutelli X.; Gruenheid, S. \& Malo, D. (2018). Enterobacteria and host resistance to infection. Mammalian Genome, 29 (7), 558-576.

Kumar, A., Alam, A., Rani, M., Ehtesham, N. Z. \& Hasnain, S. E. (2017). Biofilms: Survival and defense strategy for pathogens. International Journal of Medical Microbiology, 307 (8), 481-489.

Lewis, K. (2010). Persister cells. Annual Review of Microbiology, 64, 357-372.

Linninge, C., Roth, B., Erlanson-Albertsson, C., Molin, G., Toth, E. \& Ohlsson, B. (2018). Abundance of Enterobacteriaceae in the colon mucosa in diverticular disease. World Journal of Gastrointestinal Pathophysiology, 9 (1), 18.

Li, X. X., Shi, S., Rong, L., Feng, M. Q. \& Zhong, L. (2018). The impact of liposomal linolenic acid on gastrointestinal microbiota in mice. International Journal of Nanomedicine, 13, 1399-1409.

Loh, B., Gondil, V. S., Manohar, P., Khan, F. M., Yang, H. \& Leptihn, S. (2021). Encapsulation and delivery of therapeutic phages. Applied and Environmental Microbiology, 87 (5).

Moghimipour, E. \& Handali, S. (2013). Liposomes as drug delivery systems: properties and applications. Research Journal of Pharmaceutical, Biological and Chemical Sciences, 4 (1), 169-185.

Monteiro, N., Martins, M., Martins, A., Fonseca, N. A., Moreira, J. N., Reis, R. L. \& Neves, N. M. (2015). Antibacterial activity of chitosan nanofiber meshes with liposomes immobilized releasing gentamicin. Acta Biomaterialia, 18, 196-205.

Montso, K. P., Dlamini, S. B., Kumar, A. \& Ateba, C. N. (2019). Antimicrobial resistance factors of extended-spectrum beta-lactamases producing Escherichia coli and Klebsiella pneumoniae isolated from Cattle Farms and Raw Beef in North-West Province, South Africa. BioMed Research International, 2019.

Moyá, M. L., López-López, M., Lebrón, J. A., Ostos, F. J., Pérez, D., Camacho, V., Beck I., Bohórquez V. M., Camean M., Madinabeitia N. \& LópezCornejo, P. (2019). Preparation and characterization of new liposomes. Bactericidal activity of cefepime encapsulated into cationic liposomes. Pharmaceutics, 11 (2), 69.

Narayana, P. S. V. V. S. \& Srihari, P. S. V. V. (2019). Biofilm resistant surfaces and coatings on implants: A review. Materials Today: Proceedings, 18, 48474853.

Nicolosi, D., Cupri, S., Genovese, C., Tempera, G., Mattina, R., \& Pignatello, R. (2015). Nanotechnology approaches for antibacterial drug delivery: preparation and microbiological evaluation of fusogenic liposomes carrying fusidic acid. International Journal of Antimicrobial Agents, 45 (6), $622-626$.

OPAS-OMS (2017). OMS publica lista de bactérias para as quais se necessitam novos antibióticos urgentemente. https://www.paho.org/bra/index.php?option=com_content\&view=article\&id=5357:oms-publica-lista-de-bacterias-para-as-quais-se-necessitam-novosantibioticos-urgentemente\&Itemid=812.

Pati, N. B., Doijad, S. P., Schultze, T., Mannala, G. K., Yao, Y., Jaiswal, S., Ryan D.; Suar M.; Gwozdzinski K., Bunk B., Mraheil M. A., Hegemann J. D., Sproer C., Goesmann A., Falgenhauer L., Hain T., Imirzalioglu C., Mshana S. E., Overmann J. \& Chakraborty, T. (2018). Enterobacter bugandensis: a novel enterobacterial species associated with severe clinical infection. Scientific Reports, 8 (1), 1-11. 
Research, Society and Development, v. 10, n. 6, e15010615439, 2021

(CC BY 4.0) | ISSN 2525-3409 | DOI: http://dx.doi.org/10.33448/rsd-v10i6.15439

Porcheron G., Garénaux A., Proulx J., Sabri M. \& Dozois C. M. (2013). Iro, copper, zin, and manganese transport and regulation in pathogenic Enterobacteria: correlations between strains, site of infection and the relative importance of the differente metal transport systems for virulence. Frontiers in Cellular and Infection Microbiology, Vol. 3.

Ramos-Vivas, J., Chapartegui-González, I., Fernández-Martínez, M., González-Rico, C., Fortún, J., Escudero, R., Marco F., Linares L., Montejo M., Aranzamendi M., Muñoz P., Valerio M., Aguado J. M., Resino E., Ahufnger I. G., Veja A. P., Martínez-Martínez L. \& Fariñas, M. C. (2019). Biofilm formation by multidrug resistant Enterobacteriaceae strains isolated from solid organ transplant recipients. Scientific Reports, 9 (1), 1-10.

Rukavina, Z. \& Vanić, Ž. (2016). Current trends in development of liposomes for targeting bacterial biofilms. Pharmaceutics, 8 (2), 18.

Ruppé, E., Andremont, A. \& Armand-Lefèvre, L. (2018). Digestive tract colonization by multidrug-resistant Enterobacteriaceae in travellers: an update. Travel Medicine and Infectious Disease, 21, 28-35.

Santos, A. L., Dos Santos, A. P., Ito, C. R. M., Queiroz, P. H. P. D., de Almeida, J. A., de Carvalho Júnior, M. A. B., Oliveira C. Z., Avelino M. A. G., Wastowski I. J., Gomes G. P. L. A.; Souza A. C. S., Vasconcelos L. S. N. O. L., Santos M. O., Silva C. A. \& Carneiro, L. C. (2020). Profile of Enterobacteria resistant to beta-lactams. Antibiotics, 9 (7), 410.

Trucillo, P., Ferrari, P. F., Campardelli, R., Reverchon, E. \& Perego, P. (2020). A supercritical assisted process for the production of amoxicillin-loaded liposomes for antimicrobial applications. The Journal of Supercritical Fluids, 163, 104842.

Vanić, Ž., Rukavina, Z., Manner, S., Fallarero, A., Uzelac, L., Kralj, M., Klaric D. A., Bogdanov A., Raffai T., Virok D. P., Fillipovic-Grcic J. \& ŠkalkoBasnet, N. (2019). Azithromycin-liposomes as a novel approach for localized therapy of cervicovaginal bacterial infections. International Journal of Nanomedicine, 14, 5957.

Vassallo, A., Silletti, M. F., Faraone, I. \& Milella, L. (2020). Nanoparticulate antibiotic systems as antibacterial agents and antibiotic delivery platforms to fight infections. Journal of Nanomaterials, 2020.

Zhang, Y. (2014). Persisters, persistent infections and the Yin-Yang model. Emerging Microbes \& Infections, 3 (1), 1-10. 